\title{
Exaggerated blood pressure response during the exercise treadmill test as a risk factor for hypertension
}

\author{
S.G. Lima ${ }^{1}$, M.F.P.M. Albuquerque ${ }^{1}$, J.R.M. Oliveira ${ }^{2}$, C.F.J. Ayres ${ }^{3}$, J.E.G. Cunha ${ }^{2}$, D.F. Oliveira ${ }^{2}$ \\ R.R. Lemos ${ }^{2}$, M.B.R. Souza ${ }^{2}$ and O. Barbosa e Silva ${ }^{4}$ \\ ${ }^{1}$ Departamento de Saúde Coletiva, Centro de Pesquisas Aggeu Magalhães, Fundação Oswaldo Cruz, Recife, PE, Brasil \\ ${ }^{2}$ Laboratório de Imunopatologia Keizo Asami, Universidade Federal de Pernambuco, Recife, PE, Brasil \\ ${ }^{3}$ Departamento de Entomologia, Centro de Pesquisas Aggeu Magalhães, Fundação Oswaldo Cruz, Recife, PE, Brasil \\ ${ }^{4}$ Laboratório de Ergometria, Universidade Federal de Pernambuco, Recife, PE, Brasil
}

\begin{abstract}
Exaggerated blood pressure response (EBPR) during the exercise treadmill test (ETT) has been considered to be a risk factor for hypertension. The relationship of polymorphisms of the renin-angiotensin system gene with hypertension has not been established. Our objective was to evaluate whether EBPR during exercise is a clinical marker for hypertension. The study concerned a historical cohort of normotensive individuals. The exposed individuals were those who presented EBPR. At the end of the observation period (41.7 months $=3.5$ years), the development of hypertension was analyzed within the two groups. Genetic polymorphisms and blood pressure behavior were assessed as independent variables, together with the classical risk factors for hypertension. The I/D gene polymorphism of the angiotensin-converting enzyme and M235T of angiotensinogen were ruled out as risk factors for hypertension. EBPR during ETT is not an independent influence on the chances of developing hypertension. No differences were observed between the hypertensive and normotensive individuals regarding gender $(P=0.655)$, skin color $(P=0.636)$, family history of hypertension $(P=0.225)$, diabetes mellitus $(P=$ $0.285)$, or hypertriglyceridemia $(P=0.734)$. The risk of developing hypertension increased with increasing body mass index (BMI) and advancing age. The risk factors, which independently influenced the development of hypertension, were age and BMI. EBPR did not constitute an independent risk factor for hypertension and is probably a preclinical phase in the spectrum of normotension and hypertension.
\end{abstract}

Key words: Hypertension; Risk factors; Exaggerated blood pressure response

\section{Introduction}

Owing to the importance of hypertension as a public health problem, treatment strategies should aim to combat the risk factors that influence its development, with knowledge about these factors representing a fundamental issue. Among the factors involved in the etiopathogeny of hypertension, one third are of a genetic nature (1). However, many studies may have underestimated the impact of these genes, since behavioral patterns such as obesity, excessive alcohol consumption, exercise, among other classical risk factors, can also be modulated by genetic factors (2). Several genes, which encode the renin-angiotensin system proteins, have been implicated in the etiopathogeny of hypertension, although there are conflicting results amongst studies (3).
The exaggerated blood pressure response (EBPR) during the exercise treadmill test (ETT) has also been considered to be an independent risk factor for developing hypertension $(4,5)$. It is estimated that the probability of normotensive individuals with EBPR becoming hypertensive would be 4 or 5 times greater than that displayed by normotensives with normal blood pressure during the ETT (6). Some authors, however, do not corroborate these findings (7).

Due to the need of obtaining a better understanding of the influence of EBPR in determining hypertension, the aim of this study was to analyze the association between EBPR and hypertension, controlling the effect of the classical risk factors for hypertension and the genetic polymorphisms in the statistical analysis. 


\section{Material and Methods}

We studied a retrospective cohort of normotensive subjects who performed the ETT between February 1998 and December 2008 in a private cardiology clinic located in the city of Recife, northeastern Brazil. The exposure of interest was EBPR and the outcome (event of the study) was the development of hypertension. First, individuals were identified to have EBPR [subjects with high systolic blood pressure (SBP) at rest to maximum effort $\geqslant 7.5 \mathrm{mmHg} / \mathrm{MET}$ (metabolic equivalents) and/or SBP at the peak of effort $\geqslant 220 \mathrm{mmHg}$ who were defined as reactive hypertensive individuals through the systolic component $(\mathrm{SRH})$ or subjects with high diastolic blood pressure (DBP) at rest to maximum effort $\geqslant 15 \mathrm{mmHg}$, from normal levels of blood pressure at rest who were defined as reactive hypertensive individuals through the diastolic component (DRH)]. A random sample similar in size to the exposed group was selected from those who presented normal blood pressure during exercise (not exposed). At the end of the observation period, the outcome (developing hypertension) was analyzed within the groups based on clinical records and data from ambulatory blood pressure monitoring (ABPM) (Figure 1).

Patients taking antihypertensives or any other drug, which could interfere with blood pressure (BP) (amiodarone, beta blockers, levothyroxine, digoxin) during the ETT, individuals undergoing diagnostic investigation for hypertension, individuals who revealed any signs of localized pain or discomfort, any cardiac rhythm or conduction disturbances, suspicion of electrocardiographic alterations due to myocardial ischemia, breath sounds compatible with pulmonary congestion or bronchospasm, and those who did not reach submaximal heart rate during the exercise, were excluded from the study.

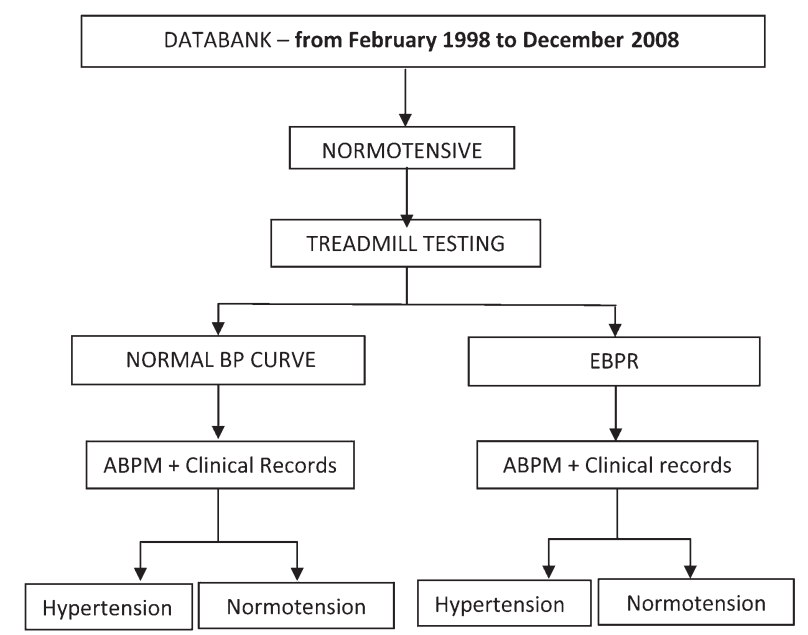

Figure 1. Study design. $B P=$ blood pressure; EBPR $=$ exaggerated $\mathrm{BP}$ response; $\mathrm{ABPM}=$ ambulatory $\mathrm{BP}$ monitoring.
Sample size was calculated with Epi-Info 2000, taking into account the following parameters: type $\alpha$ error $=$ $0.05 \%$, type $\beta$ error $=20 \%$, power of the study $=80 \%$; $\mathrm{RR}=3.0$; assuming a case frequency (hypertension) among the non-exposed group of $8 \%$ (8), which resulted in a total of 188 patients, 94 of them in the non-exposed group and 94 in the exposed group. However, due to loss prediction, all individuals who met the established inclusion criteria were included (Figure 2).

The genetic polymorphisms, BP behavior during ETT, together with the classical risk factors for hypertension [diabetes mellitus (DM), hypercholesterolemia, hypertriglyceridemia, hypertensive individuals in the immediate family, skin color, and body mass index (BMI)] were analyzed as independent variables (predictive factors). At the time of performing ABPM and analyzing the outcomes, information related to risk factors for hypertension was collected once again from both groups in order to assess if any significant changes in prevalence had taken place during the observation period, which may have interfered with the risk of developing hypertension.

Owing to the fact that BP assessment was performed by ABPM, we employed the criteria of abnormality defined for this method (9), i.e., SBP $>130 \mathrm{mmHg}$ and/or a mean DBP $>80 \mathrm{mmHg}$ or self-reported hypertension and taking antihypertensives, and normotension as a mean SBP $\leq 130 \mathrm{mmHg}$ and mean DBP $\leq 80 \mathrm{mmHg}$.

The polymorphism studies were conducted using the polymerase chain reaction (PCR). Primers employed for the angiotensinogen (AGT) gene were: FW - 5'-GGA AGG ACA AGA ACT GCA CCT C-3' and RV - 5'-CAG GGT GCT GTC CAC ACT GGA CCC C-3' (10) and the primers for the angiotensin-converting enzyme (ACE) gene were: FW - 5'-CYG GAG ACC ACT CCC ATC CTT TCT-3' and RV - 5'-GAT GTG GCC ATC ACA TTC GTC AGA T-3' (11). Analysis of ACE allele variation (I/I, I/D, and $D / D)$ was performed on $1.5 \%$ agarose gel. After amplification of the genetic region of interest of the AGT

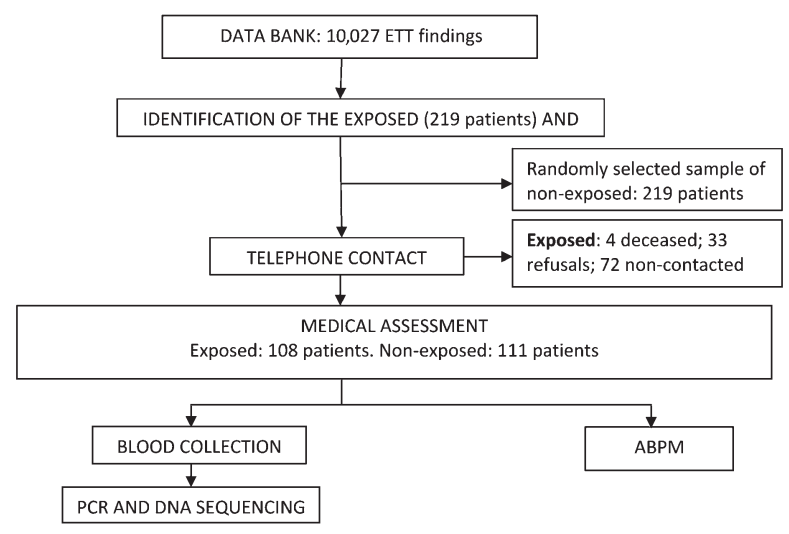

Figure 2. Flowchart of data collection. ETT = exercise treadmill test; $\mathrm{ABPM}=$ ambulatory blood pressure monitoring. 
gene polymorphism, the PCR products were purified and sequenced with a MegaBACE 1000 system (USA).

Univariate analysis was performed to determine the existence of any association between each of the studied variables and hypertension. As the age and BMI variables showed a non-linear monotonic relationship with the probability of hypertension, the non-linear variable was transformed into a linear variable by adjusting the fractional polynomials, which indicated a quadratic relationship with age and a cubic relationship with BMI. These transformations were incorporated into the models of logistic regression, employed to evaluate the association between the explicative variables and the outcome. Age, being a non-linear variable, was subdivided into deciles in order to obtain a number of similar subjects in each category, after which an odds ratio (OR) was calculated for each category, taking the youngest individuals as reference. The BMI variable was subdivided into categories related to nutritional status.

The calculated association measure was OR in lieu of $\mathrm{RR}$, since it has been employed in statistical analyses of binary outcomes in the medical literature (12) and the analysis of the effect of each independent variable on the dependent variable was controlled by the time lapse between undergoing the ETT and performing the ABPM.

In the final model, all variables, which indicated an association with an outcome of $P$ value $<0.20$ in the bivariate analysis (controlled by time), were included in the model. Selection of variables for the final multivariate model was carried out with the stepwise backward model, establishing a significance level of 0.05 for the variables remaining in the model and 0.10 for the output variables. The correlation coefficients were calculated together with their respective significances, the OR estimates and their respective confidence intervals. Hardy-Weinberg equilibrium was determined using the chi-square test.

The study protocol was approved by the CPqAM FIOCRUZ Research Ethics Committee (Registration CEP/CPqAM/FIOCRUZ: 79/07 and Registration CAAE: 0079.0.095.000-07).

\section{Results}

The study population was found to be in HardyWeinberg equilibrium. The mean observation period of this cohort was 41.7 months (3.5 years). The cumulative incidence of hypertension among the hyperreactive individuals $(21.6 \%)$ was significantly higher $(P=0.009)$ than that observed among the normoreactive individuals $(8.7 \%)$. In this sample, the probability of a normotensive individual with EBPR during ETT developing hypertension, adjusted by the time spent in the cohort, was 2.4 times greater than that of the normoreactive individuals. The incidence density of hypertension for normoreactive and hyperreactive individuals was 2.82 and $4.76 \%$, respectively. The proportion of $\mathrm{SRH}$ was found to be significantly higher amongst the individuals who developed hypertension in comparison to the DRH $(P=0.005$ $\mathrm{OR}=4.9$ vs 1.3 ).

There was no difference between hypertensive and normotensive individuals regarding gender $(P=0.655)$, skin color (0.636), a family history of hypertension $(P=$ $0.225)$, DM ( $P=0.285)$, and hypertriglyceridemia ( $P=$ $0.734)$. The prevalence of DM, hypercholesterolemia and hypertriglyceridemia in the general population was 3, 10.9 and $5.5 \%$, respectively. The proportion of individuals with hypercholesterolemia was significantly higher in the hypertensive group ( $P=0.022)$ compared to the normotensive individuals. The I/D ACE and M235T AGT polymorphisms did not constitute a risk factor for hypertension (Tables 1 and 2).

The prevalence of risk factors observed at the time of performing ABPM is presented in Table 3 . When the effect of the variable "BP behavior during ETT" was controlled by the effect of the other variables (age, BMI and hypercholesterolemia) in a multivariate logistic regression model, it was found not to have an independent influence on the risk of developing hypertension ( $P$ $=0.098$ ).

The risk of developing hypertension increased with age and BMI. The grade I and grade II obesity categories

Table 1. Analysis of the association between the I/D polymorphism of the ACE gene and hypertension.

\begin{tabular}{|c|c|c|c|c|}
\hline & Normotensive & Hypertensive & OR $(95 \% \mathrm{Cl})$ & $P^{*}$ \\
\hline \multicolumn{5}{|c|}{ Genotypes } \\
\hline $1 / 1$ & $25(83.3 \%)$ & $5(16.7 \%)$ & 1.0 & 0.755 \\
\hline $\mathrm{I} / \mathrm{D}$ & $81(87.1 \%)$ & $12(12.9 \%)$ & $0.7(0.24-2.31)$ & \\
\hline $\mathrm{D} / \mathrm{D}$ & $65(83.3 \%)$ & $13(16.7 \%)$ & $1.0(0.32-3.10)$ & \\
\hline \multicolumn{5}{|c|}{ Alleles } \\
\hline I & 131 (85.6\%) & $22(14.4 \%)$ & $0.9(0.51-1.71)$ & 0.810 \\
\hline $\mathrm{D}$ & $211(84.7 \%)$ & $38(15.3 \%)$ & 1.0 & \\
\hline
\end{tabular}

Data are reported as the number of subjects with percent within parentheses. ACE $=$ angiotensin-converting enzyme. ${ }^{*} \mathrm{Chi}$-square test. 
Table 2. Analysis of the association between the M235T polymorphism of the AGT gene and hypertension.

\begin{tabular}{|c|c|c|c|c|}
\hline & Normotensive & Hypertensive & OR $(95 \% \mathrm{Cl})$ & $\mathrm{P}^{*}$ \\
\hline \multicolumn{5}{|c|}{ Genotypes } \\
\hline $\mathrm{T} / \mathrm{T}$ & $46(85.2 \%)$ & $8(14.8 \%)$ & 1.0 & 0.839 \\
\hline $\mathrm{T} / \mathrm{C}$ & 83 (83.8\%) & $16(16.2 \%)$ & $1.1(0.44-2.79)$ & \\
\hline $\mathrm{C} / \mathrm{C}$ & $42(87.5 \%)$ & $6(12.5 \%)$ & $0.8(0.26-2.56)$ & \\
\hline \multicolumn{5}{|l|}{ Alleles } \\
\hline $\mathrm{T}$ & 175 (84.5\%) & $32(15.5 \%)$ & $0.9(0.51-1.64)$ & 0.757 \\
\hline C & 167 (85.6\%) & $28(14.4 \%)$ & 1.0 & \\
\hline
\end{tabular}

AGT $=$ angiotensinogen. ${ }^{\star}$ Exact Fisher test.

were pooled since the latter category presented a frequency in only three individuals, therefore resulting in a very wide confidence interval. The final multivariate model (with the variables, which remained at a $P$ value $<0.05$ ) is presented in Table 4 .

\section{Discussion}

Distinguishing features in the results of the present study are the lack of association between I/D ACE and M235T AGT polymorphisms and hypertension, the high prevalence of EBPR in the studied cohort and the lack of association between EBPR and hypertension.

There is no consensus in the literature with respect to the influence of I/D ACE polymorphism on BP or as a determining factor for hypertension. Some studies have shown an association of the $\mathrm{D}$ allele with hypertension $(3,13,14)$, while others have reported a complete lack of any association between the mutation and the phenotype $(3,15,16)$. The same may be observed in relation to the association between hypertension and M235T polymorphism $(13,14,17,18)$. Apart from variations in these studies regarding methodological approach, location, sample size and adjustment for confounding factors, the variability in the frequency of risk factors and their associations with hypertension in different populations may be due to complex interactions between the environment and genetic factors.

The higher EBPR prevalence encountered in the present study $(12.6 \%)$ may be partially justified by the more stringent criteria adopted for defining EBPR, which has meant that the denominator suffered a significant reduction. This may be confirmed by the adopted exclusion criteria, which included all conditions that could in any way either mask the EBPR, such as the use of antihypertensives, or bring about a rise in BP through mechanisms linked to the specific condition, and not as a $\mathrm{BP}$ response to the amount of exercise undertaken, such as chest pain and bronchospasm, among others.

When analyzing the role of EBPR in developing hypertension, Sharabi et al. (19) also reported a higher risk for SRH $(\mathrm{OR}=7.6)$ than $\mathrm{DRH}(\mathrm{OR}=5.7)$. Several investigators have found an independent association between EBPR and hypertension $(5,20,21)$. Other studies,

Table 3. Prevalence of risk factors for hypertension in normoreactive and hyperreactive individuals.

\begin{tabular}{|c|c|c|c|c|}
\hline Risk factor & Normoreactive group & $\mathrm{SRH}$ & $\mathrm{DRH}$ & $\mathrm{P}$ \\
\hline Age (years) & 44.6 & 60.7 & 46.5 & $<0.001^{*}$ \\
\hline BMI $\left(\mathrm{kg} / \mathrm{m}^{2}\right)$ & 25.5 & 27.6 & 25.9 & $0.011^{*}$ \\
\hline \multicolumn{5}{|l|}{ Gender } \\
\hline Male & $48(49.0 \%)$ & $19(19.4 \%)$ & $31(31.6 \%)$ & $0.902^{+}$ \\
\hline Female & $63(52.1 \%)$ & $22(18.2 \%)$ & $36(29.8 \%)$ & \\
\hline Diabetes mellitus & $6(40.0 \%)$ & $7(46.7 \%)$ & $2(13.3 \%)$ & $0.013^{+}$ \\
\hline Dyslipidemia & $36(55.4 \%)$ & $17(26.2 \%)$ & $12(18.5 \%)$ & $0.023^{+}$ \\
\hline Family history of hypertension & $73(51.4 \%)$ & $19(13.4 \%)$ & $50(35.2 \%)$ & $0.011^{+}$ \\
\hline Smoking & $5(27.8 \%)$ & $5(27.8 \%)$ & $8(44.4 \%)$ & $0.110^{+}$ \\
\hline Adding salt to food & $26(51.0 \%)$ & $16(31.4 \%)$ & $9(17.7 \%)$ & $0.973^{+}$ \\
\hline Sedentarism & $54(49.5 \%)$ & $24(22.0 \%)$ & $31(28.4 \%)$ & $0.053^{+}$ \\
\hline Stress & $62(51.2 \%)$ & $23(19.0 \%)$ & $36(29.8 \%)$ & $0.940^{+}$ \\
\hline
\end{tabular}

Data are reported as the number of subjects with percent within parentheses, except for age and BMI. SRH = reactive hypertension through the systolic component; $\mathrm{DRH}=$ reactive hypertension through the diastolic component; $\mathrm{BMI}=$ body mass index. *Student $t$-test; ${ }^{+}$chi-square test. 
Table 4. Multivariate analysis of the association between risk factors, which remained in the model with a $P$ value $<0.05$, and hypertension.

\begin{tabular}{|c|c|c|c|c|c|c|}
\hline Variable & Reference* & $\mathrm{N}$ & Hypertension (\%) & $\mathrm{P}$ & Adjusted OR ${ }^{+}$ & $95 \% \mathrm{Cl}$ \\
\hline Age (years) & & & & 0.005 & & \\
\hline 18 to 27 & 21.5 & 24 & 12.5 & & 1.0 & - \\
\hline 28 to 33 & 30.5 & 20 & 5.0 & & 1.2 & 1.03 to 1.41 \\
\hline 34 to 37 & 36.0 & 15 & 0.0 & & 1.4 & 1.06 to 1.83 \\
\hline 38 to 41 & 40.0 & 18 & 0.0 & & 1.6 & 1.08 to 2.29 \\
\hline 42 to 44 & 43.0 & 22 & 27.3 & & 1.7 & 1.10 to 2.74 \\
\hline 45 to 47 & 46.0 & 19 & 10.5 & & 1.9 & 1.12 to 3.33 \\
\hline 48 to 52 & 50.0 & 24 & 20.8 & & 2.3 & 1.15 to 4.40 \\
\hline 53 to 57 & 53.0 & 21 & 14.3 & & 2.5 & 1.18 to 5.51 \\
\hline 58 to 63 & 60.5 & 18 & 22.2 & & 3.6 & 1.25 to 10.23 \\
\hline 64 to 76 & 70.0 & 20 & 30.0 & & 5.9 & 1.37 to 25.18 \\
\hline BMI $\left(\mathrm{kg} / \mathrm{m}^{2}\right)$ & & & & $<0.001$ & & \\
\hline 16.0 to 18.4 & 17.2 & 7 & 0.0 & & 1.0 & - \\
\hline 18.5 to 24.9 & 21.7 & 96 & 10.4 & & 1.6 & 1.26 to 2.07 \\
\hline 25.0 to 29.9 & 27.5 & 80 & 15.0 & & 4.2 & 2.01 to 8.98 \\
\hline 30.0 to 39.9 & 35.0 & 18 & 44.4 & & 32.6 & 5.36 to 198.06 \\
\hline Period of cohort (years) & - & - & - & 0.008 & 1.2 & 1.0 to 1.4 \\
\hline
\end{tabular}

$\mathrm{BMI}=$ body mass index. ${ }^{*}$ midpoint of the class; ${ }^{+}$adjusted model: logistic (probability of hypertension) $=-5.19+0.0141$ period of cohort $+0.0004 \mathrm{age}^{2}+0.0001 \mathrm{BMI}^{3}$. Significance of model variables: time of the cohort $(\mathrm{P}=0.038) ; \mathrm{age}^{2}(\mathrm{P}=0.017) ; \mathrm{BMI}^{3}$ $(\mathrm{P}<0.001)$.

on the other hand, have concluded that EBPR is not a risk factor for hypertension (7). Multivariate analysis of the present data did not indicate an independent effect of EBPR as a risk factor for hypertension. Under these circumstances, and taking into account a number of other studies, which have presented a positive association, it is worth highlighting not only the importance of defining the criteria for EBPR, but also questions related to sample heterogeneity, type of ergometer, procedures employed during exercise, statistical analysis model, and even subjective variation while measuring $\mathrm{BP}$.

There is no uniformity in the criteria employed by many of the studies in order to define EBPR (22). Some authors only consider the systolic component of BP to define EBPR $(21,23)$, while others take gender into account (24). With regard to tension levels, which are used as a cutoff point to define EBPR, the heterogeneity of opinions is even greater, both for SBP and DBP $(19,20)$. However, the majority of authors do not consider the relationship with the amount of exercise undertaken. When SBP level is divided by the number of METs, an index is established, which may indicate an EBPR for the amount of exercise (25). With regard to the DBP, on the other hand, the variation between rest and maximum effort seems much more representative of the real BP behavior than the maximum level of DBP reached, as many investigators have adopted.

Another factor, which should be taken into account, is the duration of the observation period, from undertaking the stress test until the time of ascertaining the outcome.
Although the variables have been adjusted with regard to the time of exposure (the observation period of the cohort), it is nonetheless considered that a period of approximately 4 years is still not enough for hypertension to become apparent. This may therefore justify both the low incidence of hypertension in this population and the lack of association between EBPR and hypertension.

One possible explanation for the lack of association between BP behavior during ETT and hypertension is that the effect attributed to EBPR when developing hypertension may have been counterbalanced by the modification of the risk profile of the normoreactive and hyperreactive groups after undertaking the ETT. Data concerning the risk factors collected at the time of performing the ABPM revealed that there were fewer risk factors in the hyperreactive individuals than in the normoreactive individuals. This fact may have contributed to reducing the risk within this group, despite the influence of EBPR encountered within the group.

Another explanation seems much more probable, however: it is possible that the association between EBPR and hypertension, as confirmed by the literature, qualifies EBPR not as a risk factor for hypertension, but rather as a pre-hypertensive condition (disease marker/ preclinical condition). Thus, in the natural history of hypertension, departing from a condition of normotension to hypertension, there would be an intermediary stage characterized by EBPR during exercise, which occurs as a consequence of the risk factors that directly influence the onset of hypertension, such as age and BMI. In other 
words, during the life history of a hypertensive individual, there would be a coming together of risk factors, which would ultimately contribute to the move from a normotensive condition with EBPR to hypertension. The hypothesis of this study can be still based on the observations of Carretero and Oparil (26), according to whom genetic susceptibility continues to be added to other risk factors and, because of this, the BP curve progressively starts shifting to the right, indicating that the individual is moving from a normotensive condition towards a hypertensive condition.

Among the classical risk factors for hypertension, only age and BMI have been shown to have an independent association with the development of hypertension. Risk increases with age, and is 3 times greater in hypertensive individuals in the age range between 64 and 76 than in normotensive individuals. Cipullo et al. (27) also reported the progressive increase of the risk with advancing age up to 69 years of age. Other studies have also reported age as a risk factor for hypertension (28).

An increased BMI has also shown a direct relation to increased risk. Risk estimates based on the Framingham Study suggest that about $75 \%$ of men and $65 \%$ of women suffer from hypertension as a direct result of being overweight (29). The INTERSALT Study indicated a correlation between BMI and both SBP and DBP regardless of age, alcohol consumption, smoking, and urinary sodium excretion (30).

It is possible that the lack of association between risk factors such as DM, hypercholesterolemia and hypertriglyceridemia and hypertension (28) has suffered the influence of a low incidence of hypertension in the population studied here. In Brazil, the prevalence of hypertension, as described in the literature, ranges from 24.8 to $44.4 \%(31,32)$. The prevalence of hypercholesterolemia and hypertriglyceridemia in this sample is also found to be below the median of the prevalence in national studies (33). These prevalences may have suffered an

\section{References}

1. Poch E, Gonzalez D, Giner V, Bragulat E, Coca A, de la Sierra A. Molecular basis of salt sensitivity in human hypertension. Evaluation of renin-angiotensin-aldosterone system gene polymorphisms. Hypertension 2001; 38: 12041209, doi: 10.1161/hy1101.099479.

2. Krieger JE, Pereira AC. Genética da hipertensão arterial. In: Brandão A (Editor), Hipertensão. 1st edn. Rio de Janeiro: Elsevier; 2006. p 17-24.

3. Lima SG, Hatagima A, Silva NL. Renin-angiotensin system: is it possible to identify hypertension susceptibility genes? Arq Bras Cardiol 2007; 89: 427-433.

4. Matthews CE, Pate RR, Jackson KL, Ward DS, Macera CA, Kohl $\mathrm{HW}$, et al. Exaggerated blood pressure response to dynamic exercise and risk of future hypertension. J Clin Epidemiol 1998; 51: 29-35, doi: 10.1016/S0895-4356(97)00223-0.

5. Miyai N, Arita M, Miyashita K, Morioka I, Shiraishi T, Nishio I. Blood pressure response to heart rate during exercise test information bias, since information regarding cholesterol levels, triglycerides and glucose was obtained through anamnesis and not by direct blood determinations. In agreement with the results of the present study, other investigators have also found a lack of association between hypertension and gender $(27,34)$, skin color $(35,36)$ and a history of hypertension in the immediate family (27). The possibility of selection bias in the present study could be mitigated, since the exposed and nonexposed individuals came from the same population. The outcome was analyzed by a single observer and the same standardized methods were employed to detect it.

The main contribution of the present study is to understand EBPR not as a risk factor, but rather as an intermediary condition between normotension and hypertension. Since the structural alterations in this evolutionary phase of hypertension have been described, the development of specific healthcare strategies is necessary as a secondary prevention policy, aiming to reduce lesions and, as a consequence, the risks of EBPR sufferers. A primary prevention strategy would be to address risk factors as a form of preventing the evolution from a healthy state to the disease (from normotension to normotension with EBPR).

The risk factors, which independently influenced the development of hypertension, were age and BMI. The I/D polymorphism of ACE and the M235T of AGT revealed no association with the development of hypertension in the study population. Although univariate analysis revealed an association between EBPR and the development of hypertension, it did not constitute an independent risk factor for hypertension, and is probably a preclinical phase of the health-hypertension spectrum.

\section{Acknowledgments}

\author{
Research supported by FACEPE.
}

and risk of future hypertension. Hypertension 2002; 39: 761766, doi: $10.1161 /$ hy0302.105777.

6. Brito FS, Vilas-Boas F, Castro I, Oliveira JA, Guimarães JI, Stein R, et al. II Diretrizes da Sociedade Brasileira de Cardiologia sobre teste ergométrico. Arq Bras Cardiol 2002; 78 (Suppl 2): 1-17, doi: 10.1590/S0066782X2002000800001.

7. Lauer MS, Levy D, Anderson KM, Plehn JF. Is there a relationship between exercise systolic blood pressure response and left ventricular mass? The Framingham Heart Study. Ann Intern Med 1992; 116: 203-210.

8. Allison TG, Cordeiro MA, Miller TD, Daida H, Squires RW, Gau GT. Prognostic significance of exercise-induced systemic hypertension in healthy subjects. Am J Cardiol 1999; 83: 371-375, doi: 10.1016/S0002-9149(98)00871-6.

9. Alessi A, Brandao AA, Pierin A, Feitosa AM, Machado CA, de Moraes Forjaz CL, et al. [IV Guideline for ambulatory 
blood pressure monitoring. II Guideline for home blood pressure monitoring. IV ABPM/II HBPM]. Arq Bras Cardiol 2005; 85 (Suppl 2):: 1-18, doi: 10.1590/S0066782X2005002100001.

10. Araújo MS, Menezes BS, Lourenço C, Cordeiro ER, Gatti RR, Goulart LR. O gene do angiotensinogênio (M235T) e o infarto agudo do miocárdio. Rev Assoc Med Bras 2005; 51: 164-169, doi: 10.1590/S0104-42302005000300018.

11. Alvarez R, Reguero JR, Batalla A, Iglesias-Cubero G, Cortina A, Alvarez V, et al. Angiotensin-converting enzyme and angiotensin II receptor 1 polymorphisms: association with early coronary disease. Cardiovasc Res 1998; 40: 375379, doi: 10.1016/S0008-6363(98)00179-5.

12. Kirkwood BR, Stern JAC. Medical statistics. 2nd edn. Malden: Blackwell Science; 2003.

13. Ji LD, Zhang LN, Shen P, Wang P, Zhang YM, Xing WH, et al. Association of angiotensinogen gene M235T and angiotensin-converting enzyme gene I/D polymorphisms with essential hypertension in Han Chinese population: a meta-analysis. J Hypertens 2010; 28: 419-428, doi: 10.1097/HJH.0b013e32833456b9.

14. Mondry A, Loh M, Liu P, Zhu AL, Nagel M. Polymorphisms of the insertion/deletion ACE and M235T AGT genes and hypertension: surprising new findings and meta-analysis of data. BMC Nephrol 2005; 6: 1, (Abstract)., doi: 10.1186/ 1471-2369-6-1

15. Eisenmann JC, Sarzynski MA, Glenn K, Rothschild M, Heelan KA. ACE I/D genotype, adiposity, and blood pressure in children. Cardiovasc Diabetol 2009; 8: 14, doi: 10.1186/1475-2840-8-14.

16. Agerholm-Larsen B, Nordestgaard BG, Tybjaerg-Hansen A. ACE gene polymorphism in cardiovascular disease: metaanalyses of small and large studies in whites. Arterioscler Thromb Vasc Biol 2000; 20: 484-492, doi: 10.1161/ 01.ATV.20.2.484

17. van den Born $B J$, van Montfrans $G A$, Uitterlinden $A G$, Zwinderman AH, Koopmans RP. The M235T polymorphism in the angiotensinogen gene is associated with the risk of malignant hypertension in white patients. J Hypertens 2007; 25: 2227-2233, doi: 10.1097/HJH.0b013e3282efb213.

18. Niu W, Qi Y, Cen W, Cui C, Zhuoma C, Cai D, et al. Genetic polymorphisms of angiotensinogen and essential hypertension in a Tibetan population. Hypertens Res 2007; 30: 11291137, doi: 10.1291/hypres.30.1129.

19. Sharabi Y, Ben-Cnaan R, Hanin A, Martonovitch G, Grossman E. The significance of hypertensive response to exercise as a predictor of hypertension and cardiovascular disease. J Hum Hypertens 2001; 15: 353-356, doi: 10.1038/ sj.jhh.1001157.

20. Everson SA, Kaplan GA, Goldberg DE, Salonen JT. Anticipatory blood pressure response to exercise predicts future high blood pressure in middle-aged men. Hypertension 1996; 27: 1059-1064, doi: 10.1161/01.HYP.27.5.1059.

21. Farah R, Shurtz-Swirski R, Nicola M. High blood pressure response to stress ergometry could predict future hypertension. Eur J Intern Med 2009; 20: 366-368, doi: 10.1016/ j.ejim.2008.09.016.

22. Marsaro EA, Vasquez EC, Lima EG. [Blood pressure assessment in normoreactive and hyperreactive patients. A comparative study between casual and ambulatory blood pressure monitoring]. Arq Bras Cardiol 1996; 67: 319-324.

23. Jae SY, Fernhall B, Heffernan KS, Kang M, Lee MK, Cho $\mathrm{YH}$, et al. Exaggerated blood pressure response to exercise is associated with carotid atherosclerosis in apparently healthy men. J Hypertens 2006; 24: 881-887, doi: 10.1097/ 01.hjh.0000222758.54111.e2.

24. Chang HJ, Chung J, Choi SY, Yoon MH, Hwang GS, Shin $\mathrm{JH}$, et al. Endothelial dysfunction in patients with exaggerated blood pressure response during treadmill test. Clin Cardiol 2004; 27: 421-425, doi: 10.1002/clc.4960270713.

25. Hespanha R. Função respiratória. In: Hespanha R (Editor), Ergometria. Bases fisiológicas e metodologia para a prescrição de exercício. 1st edn. Rio de Janeiro: Rubio; 2004. p 53-70.

26. Carretero OA, Oparil S. Essential hypertension. Part I: definition and etiology. Circulation 2000; 101: 329-335, doi: 10.1161/01.CIR.101.3.329.

27. Cipullo JP, Martin JF, Ciorlia LA, Godoy MR, Cacao JC, Loureiro AA, et al. [Hypertension prevalence and risk factors in a Brazilian urban population]. Arq Bras Cardiol 2010; 94 519-526, doi: 10.1590/S0066-782X2010005000014.

28. Anonymous. $\vee$ Diretrizes Brasileiras de Hipertensão Arterial. São Paulo: Sociedade Brasileira de Cardiologia; 2006.

29. Garrison RJ, Kannel WB, Stokes J III, Castelli WP Incidence and precursors of hypertension in young adults: the Framingham Offspring Study. Prev Med 1987; 16: 235251, doi: 10.1016/0091-7435(87)90087-9.

30. Dyer AR, Elliott $P$, Shipley $M$. Body mass index versus height and weight in relation to blood pressure. Findings for the 10,079 persons in the INTERSALT Study. Am J Epidemiol 1990; 131: 589-596.

31. Gus I, Harzheim E, Zaslavsky C, Medina C, Gus M. Prevalence, awareness, and control of systemic arterial hypertension in the state of Rio Grande do Sul. Arq Bras Cardiol 2004; 83: 429-433, doi: 10.1590/S0066-782X2004001700009.

32. de Souza AR, Costa A, Nakamura D, Mocheti LN, Stevanato Filho PR, Ovando LA. A study on systemic arterial hypertension in Campo Grande, MS, Brazil. Arq Bras Cardiol 2007; 88: 441-446, doi: 10.1590/S0066782X2007000400013.

33. Bloch KV, Rodrigues CS, Fiszman R. Epidemiologia dos fatores de risco para hipertensão arterial - uma revisão crítica da literatura brasileira. Rev Bras Hipertens 2006; 13: 134-143.

34. Kearney PM, Whelton M, Reynolds K, Muntner P, Whelton PK, He J. Global burden of hypertension: analysis of worldwide data. Lancet 2005; 365: 217-223.

35. Gillum RF. Pathophysiology of hypertension in blacks and whites. A review of the basis of racial blood pressure differences. Hypertension 1979; 1: 468-475, doi: 10.1161/ 01.HYP.1.5.468.

36. Centers for Disease Control and Prevention (USA). Racial/ ethnic disparities in prevalence, treatment, and control of hypertension - United States, 1999-2002. Morbidity Mortality Weekly Report 2005; 54: 7-9. 